\title{
COVID-19-associated liver injury: from bedside to bench
}

\author{
Dongxiao $\mathrm{Li}^{1} \cdot \mathrm{Xiangming}^{\mathrm{Ding}}{ }^{2} \cdot \mathrm{Meng} \mathrm{Xie}^{1} \cdot \operatorname{Dean}_{\mathrm{Tian}^{1}} \cdot \mathrm{Limin}_{\mathrm{Xia}^{1}}$
}

Received: 25 August 2020/ Accepted: 4 January 2021/Published online: 1 February 2021

(C) Japanese Society of Gastroenterology 2021

\begin{abstract}
The outbreak of coronavirus disease 2019 (COVID-19), caused by severe acute respiratory syndrome coronavirus 2 (SARS-CoV-2), has been a global challenge since December 2019. Although most patients with COVID-19 exhibit mild clinical manifestations, in approximately $5 \%$ of these patients, the disease eventually progresses to severe lung injury or even multiorgan dysfunction. This situation represents various challenges to hepatology. In the context of liver injury in patients with COVID-19, several key problems need to be solved. For instance, it is important to determine whether SARS-CoV2 can directly invade liver, especially when ACE2 appears to be negligibly expressed on hepatocytes. In addition, the mechanisms underlying liver dysfunction in COVID-19 patients are not fully understood, which are likely multifactorial and related to hyperinflammation, dysregulated immune responses, abnormal coagulation and drugs. Here, we systematically describe the potential pathogenesis of COVID-19-associated liver injury and propose several hypotheses about its etiopathogenesis.
\end{abstract}

Keywords COVID-19 · Liver injury · SARS-CoV-2 . Pathogenesis · Hyperinflammation

Dongxiao Li and Xiangming Ding contributed equally to this work.

Limin Xia

xialimin@tjh.tjmu.edu.cn

1 Department of Gastroenterology, Institute of Liver and Gastrointestinal Diseases, Hubei Key Laboratory of Hepato-

Pancreato-Biliary Diseases, Tongji Hospital of Tongji

Medical College, Huazhong University of Science and

Technology, Wuhan 430030, Hubei Province, China

2 Department of Gastroenterology, Henan Provincial People's Hospital, Zhengzhou 450000, Henan Province, China

$\begin{array}{ll}\text { Abbreviations } \\ \text { COVID-19 } & \text { Coronavirus disease 2019 } \\ \text { SARS- } & \text { Severe acute respiratory syndrome } \\ \text { CoV-2 } & \text { coronavirus } 2 \\ \text { ALT } & \text { Alanine aminotransferase } \\ \text { AST } & \text { Aspartate aminotransferase } \\ \text { GGT } & \text { Gamma-glutamyl transferase } \\ \text { ALP } & \text { Alkaline phosphatase } \\ \text { TBIL } & \text { Total bilirubin } \\ \text { ACE2 } & \text { Angiotensin-converting enzyme II } \\ \text { TMPRSS2 } & \text { Transmembrane serine protease 2 } \\ \text { BECs } & \text { Biliary epithelial cells } \\ \text { RAS } & \text { Renin-angiotensin-aldosterone system } \\ \text { CRP } & \text { C-reactive protein } \\ \text { CRS } & \text { Cytokine release syndrome } \\ \text { AT1R } & \text { Angiotensin receptor type 1 } \\ \text { ADAM17 } & \text { Metalloprotease 17 } \\ \text { ADE } & \text { Antibody-dependent enhancement } \\ \text { sHLH } & \text { Hemophagocytic lymphohistiocytosis } \\ \text { PAMPs } & \text { Pathogen-associated molecular patterns } \\ \text { DAMPs } & \text { Damage-associated molecular patterns } \\ \text { MAS } & \text { Macrophage activation syndrome } \\ \text { NETs } & \text { Neutrophil extracellular traps } \\ \text { ARDS } & \text { Acute respiratory distress syndrome } \\ \text { SIRS } & \text { Systemic inflammatory response syndrome } \\ \text { MOF } & \text { Multiple organ failure } \\ \text { MODS } & \text { Multiple organ dysfunction syndrome } \\ \text { CLD } & \text { Chronic liver disease } \\ & \end{array}$

Abbreviations

SARS-

$\mathrm{CoV}-2$

AST

GGT

ALP

ACE2

TMPRSS2

CRP

CRS

ADAM17

ADE

SHLH

PAMPs

DAMPS

MAS

NETs

ARDS

SIRS

MODS

Chronic liver disease 


\section{Introduction}

Since December 2019, the severe acute respiratory syndrome coronavirus 2 (SARS-CoV-2) outbreak, which was first reported in Wuhan, China, has become a serious threat to global public health [1]. On March 12, 2020, the World Health Organization (WHO) declared that coronavirus disease 2019 (COVID-19) caused by SARS-CoV-2 constituted a pandemic. Although most patients infected with SARS-CoV-2 exhibit mild respiratory symptoms, approximately $5 \%$ of patients develop severe lung injury or even multiorgan dysfunction, resulting in increased mortality [2].

Liver dysfunction or injury, characterized by liver test abnormalities, have been reported in patients with COVID$19[3,4]$. Biochemical abnormalities in the liver, such as elevated alanine aminotransferase (ALT), aspartate aminotransferase (AST), gamma-glutamyl transferase (GGT), alkaline phosphatase (ALP) and/or total bilirubin (TBIL) levels, were associated with increased risks of mortality [5, 6]. However, the pathophysiological and immunological mechanisms of liver injury in patients with COVID-19 are poorly understood. Understanding the fundamental physiological and immunological processes of COVID-19-associated liver injury is vital for the identification and rational design of effective therapies.

\section{Angiotensin-converting enzyme-2 (ACE2)- mediated direct cytopathic effects of SARS-CoV-2}

Whether SARS-CoV-2 can directly target the liver, specifically hepatocytes, is unknown and has been widely studied. Reports on a limited number of liver biopsy samples from COVID-19 patients showed moderate microvesicular steatosis, slightly watery degeneration or necrosis of hepatocytes, mild sinusoidal dilatation, and lymphocytic endotheliitis, indicating the liver injury might be caused by SARS-CoV-2 infection [7, 8]. SARS-CoV2 viral load has been tested in about $48 \%$ of patients even with respiratory samples tested negative and SARS-CoV-2 nucleocapsid was detected in the cytoplasm of intestinal biopsies, which indicated a plausible hypothesis that viruses could enter the portal circulation to reach the liver $[9,10]$. Nebuloni et al. detected the SAR-CoV-2 virions in the hepatic vessel lumen and endothelial cells by in situ hybridization [7]. Evidence for direct hepatic infection was provided by showing SARS-CoV-2 particles in the cytoplasm of hepatocytes of COVID-19 patients with hepatic dysfunction [11]. Zhao et al. reported that typical coronavirus particles, characterized by spike structures, were observed in the cytoplasm of hepatocytes in COVID-19 cases. SARS-CoV-2 directly contributed to cytopathy based on the ultrastructural features of conspicuous mitochondria swelling, endoplasmic reticulum dilatation, glycogen granule decreased, and impaired cell membranes in the infected hepatocytes [12]. Notably, there is no confirmatory PCR testing for viral nucleic acids performed in the spiked inclusions and their degenerate components, leaving the possibility that these spiked particles may not be of viral origin $[12,13]$. Whereas SARS-CoV viral RNA was shown to be detected in the liver tissues by PCR testing at the time of SARS pandemic [14], and recent virus detection studies have shown that the sequence of the current new coronavirus has $79.6 \%$ homology with SARS$\mathrm{CoV}$ [15]. All the aforementioned findings imply that liver injury in COVID-19 patients might be partially caused by a direct attack by the virus.

ACE2 have been identified as the predominant entry receptor of both SARS-CoV and SARS-CoV-2 [16]. SARS-CoV-2 is perceived to be less likely infect the liver via ACE2 due to the low percentage of hepatocytes expressing ACE2 [9, 10]. However, receptor abundance may not be always consistent with organ symptoms. For instance, the expression of ACE2 in the lung is not significantly higher than that in intestinal epithelia or bladder urothelial cells, but respiratory symptomatology is substantially more severe than other organs [17]. Besides, even in the lung, ACE2 is expressed in only $0.64 \%$ of all human lung cell and $1.4 \%$ alveolar type II (AT2) epithelial cell [18]. Another issue of concern is whether the expression of ACE2 in hepatocytes will increase in response to SARSCoV-2 infection, systemic inflammation or liver injury. Recent evidence suggests that the transactivation of ACE2 may be triggered by inflammatory signals, such as type I interferon or IL-6 during SARS-CoV-2 infection [19, 20]. Thus, further study on the expression of ACE2 in SARSCoV-2-infected liver is necessary to address this hypothesis.

Single-cell RNA-seq analysis revealed a significant enrichment of ACE2 expression in cholangiocytes cluster, and ACE2 expression in cholangiocytes is comparable to AT2 cells $[17,21]$. The increased expression of viral mRNA at $24 \mathrm{~h}$ after the infection was confirmed in the infected human liver ductal organoids with SARS-CoV-2 [22]. Besides, ALP and GGT levels, biomarkers of cholangiocyte injury, have indeed been shown to be elevated in some COVID-19 patients with liver dysfunction [5]. In a recent report by Han and colleagues, SARS-CoV-2 viral RNA was detected in the bile specimen from a severe COVID-19 patient by PCR testing [23]. The viral load in the bile was much higher than that in the sputum, suggesting that the false-positive rate in the specimen was relatively low. A latest study by Zhao et al. also revealed that SARS-CoV-2 infection impairs the barrier and bile 
acid transporting functions of cholangiocytes [22]. Thus, it's reasonable to speculate that SARS-CoV2 viral load detected in stool samples may be at least partly derived from bile juice [23]. These findings imply that liver injury in COVID-19 patients might be partially due to viral invasion of ACE2-positive cholangiocytes (Fig. 1a). Alternatively, the finding of upregulated ACE2 expression in hepatocytes during compensatory hyperplasia in response to viral infection or liver injury inspired us to speculate some regenerative hepatocytes originate from cholangiocytes may facilitate viral infection in turn.

\section{Alternative pathways for SARS-CoV-2 infection of the liver}

Evidently, the direct effect of SARS-CoV-2 on the liver may not be fully achieved through ACE2, and other receptors cannot be excluded (Fig. 1b-d). Based on previous studies of SARS-CoV, DC-SIGN and/or L-SIGN, are thought as alternative receptors or as enhancer factors that facilitate ACE2-mediated virus infection [24]. It's worth noting that L-SIGN is a liver-specific capture receptor for virus infection and immunity [25]. A previous study suggested that the S glycoprotein of SARS-CoV may use both ACE2 and L-SIGN in virus infection and pathogenesis [26]. Besides, L-SIGN may also play a protective role in the internalization and degradation of HIV-1 [27]. More evidence is needed to determine whether L-SIGN can mediate SARS-CoV-2 entry into hepatocytes and its specific function in SARS-CoV-2 infection. CD147 is another possible receptor for SARS-CoV-2. CD147 is highly expressed in tumor tissues, inflamed tissues and pathogen-infected cells [28]. Chen et al. reported that SARS-CoV-2 invades host cells via a novel pathway of CD147-spike protein interaction [29]. Meplazumab, a humanized anti-CD147 antibody, can effectively prevent viruses from invading host cells by blocking CD147. It is not clear whether SARS-CoV-2 can use the CD147 receptor to invade hepatocytes.

Although antibodies are generally protective and beneficial, antibody-dependent enhancement (ADE) has been documented for multiple viral infections such as dengue, flavivirus, and influenza virus $[30,31]$. In ADE of infection, suboptimal nonneutralizing antibodies cannot completely neutralize the virus; instead, they attach to the Fc receptor $(\mathrm{FcR})$ expressed on target cells to promote virus entry and infection [31]. Recent studies reported that patients with severe COVID-19 cases frequently had an augmented IgG response and a higher titer of antibodies, which was associated with poor prognosis [32]. We speculate that a potential mechanism may be related to ADE of viral infection that occurs in some COVID-19 patients with early, sub-optimal antibody activity that cannot completely

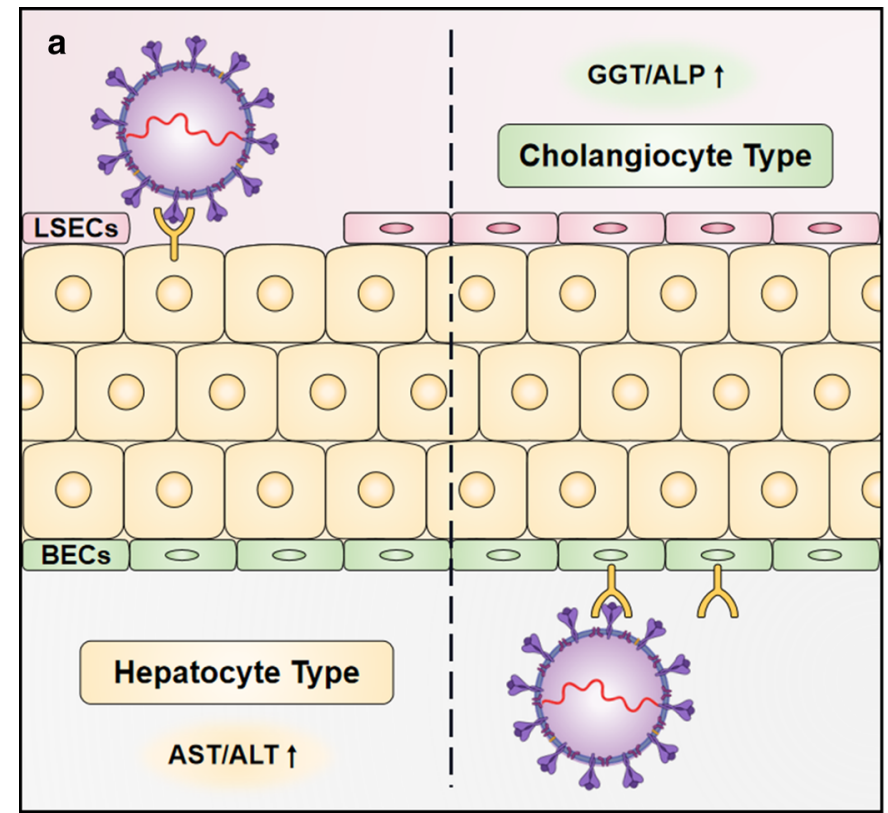

Fig. 1 Possible pathways of SARS-CoV-2 infection in the liver. a Direct SARS-CoV-2 infection targeted to hepatocytes or biliary epithelial cells (BECs) is defined as the hepatocellular type or cholangiocyte type, respectively. b-e ACE2 in conjunction with TMPRSS2 is considered the predominant receptor for SARS-CoV-2 entry into cells. In addition, L-SIGN (CD209L) and CD147 may
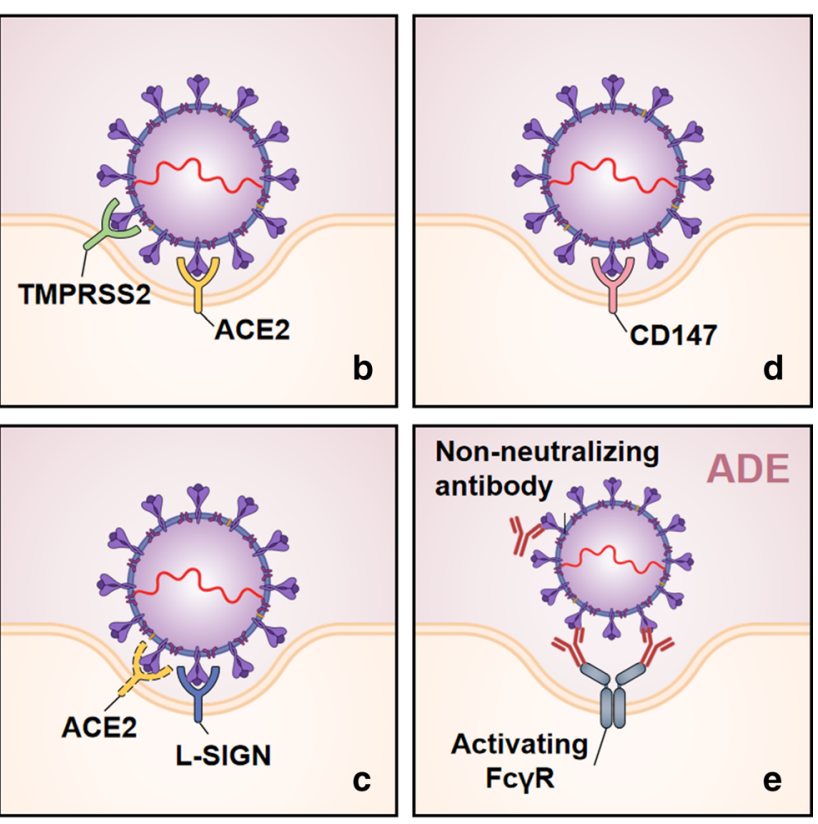

function as possible alternative cell receptors for SARS-CoV-2. Furthermore, antibody-dependent enhancement (ADE) may induce SARS-CoV-2 infection of hepatocytes as well. During ADE of infection, suboptimal nonneutralizing antibodies cannot completely neutralize the virus; instead, they attack the $\mathrm{Fc}$ receptor $(\mathrm{FcR})$ expressed on target cells, leading to virus entry and infection 
eliminate the virus, but instead leads to persistent viral replication and inflammation (Fig. 1e) [33]. Besides, virusneutralizing antibody immune complexes can promote inflammation and tissue injury by activating macrophages via FcRs [34]. These findings indicate that ADE should be given full consideration in the safety evaluation of emerging candidate vaccines for SARS-CoV-2.

\section{Cytokine release syndrome (CRS) and renin- angiotensin-aldosterone system (RAS)}

Cytokine release syndrome was regarded as the prominent cause of fatality in the previous SARS-CoV and MERS$\mathrm{CoV}$ infections [35]. Similarly, a cytokine profile including IL-6, IL-10 and C-reactive protein (CRP) in severe COVID-19 patients with liver injury was also documented and multivariable analysis revealed that IL-6 is a potential risk factors in patients with COVID-19 developing severe liver injury [36, 37]. IL-6 is a pleiotropic four-helix-bundle cytokine that exerts multiple functions in the liver. It is not only implicated in acute phase response and infection defense, but also in liver regeneration and metabolic function of the liver [38]. IL-6 signals through two distinct pathways referred to as classic cis signaling or trans signaling. In classical cis signaling, IL-6 binds to the membrane-bound IL-6R and forms a complex with gp130, whose dimerization activated the downstream signaling mediated by JAKs and STAT3, which can contribute to CRS. The mIL-6R is only expressed on few cell types such as hepatocytes and certain immune cells, thus hepatocytes can directly respond to IL-6 [39, 40]. In trans-signaling, IL6 binds to the soluble IL-6R (sIL-6R), forming a complex with a gp130 dimer. The resultant IL-6-sIL-6R-JAKSTAT3 signaling is then activated in cells that do not express mIL-6R, such as endothelial cells, thus widens the cell type affected by IL- 6 signaling and results in a systemic "cytokine storm" [41]. The trans signaling results in CRS involving secretion of various proinflammatory cytokines and chemokines, including additional IL-6. Thus, the feedback loop of the IL-6 amplifier (IL-6 Amp) might act as a switch to activate "cytokine storms" (Fig. 2) [42]. Therefore, targeting the IL-6 signaling pathway may reverse the hyperinflammation status and curb the cytokine release syndrome in severe COVID-19 patients with liver injury.

ACE2 is considered not only a dominant receptor for both SARS viruses but also an inhibitor that physiologically counters RAS activation [43]. Specifically, ACE2 is a key counterregulatory enzyme that degrades angiotensin II (Ang II) to Ang1-7, thereby attenuating the effects of Ang II on vasoconstriction, sodium retention, and fibrosis [44]. After endocytosis of a viral complex, ACE2 is downregulated and shed from the surface of the host cell, resulting in angiotensin II accumulation; thus, local activation of the RAS may mediate tissue injury in response to viral insults [45]. In addition, the loss of hepatic ACE2 function has been suggested to induce liver inflammation and injury [46, 47]. Ang II acts not only as a vasoconstrictor but also as a proinflammatory cytokine via the angiotensin receptor type 1 (AT1R)-metalloprotease 17 (ADAM17) axis [45]. ADAM17 cleaves mIL-6R, thereby generating sIL-6R, thus activates IL-6 trans signaling in IL6R-negative cells (Fig. 2) [42]. Therefore, a better understanding of the precise role of IL- 6 in the pathogenesis of COVID-19, especially in severe cases, may help us alleviate liver injury.

\section{Hyperinflammation and dysregulated immune responses}

Several studies have now established that the hyperinflammation and dysregulated immune responses induced by SARS-CoV-2 may lead to harmful tissue damage, both locally and systemically [48-50]. Increase of neutrophil counts, decreased number of $\mathrm{T}$ lymphocyte subsets, including $\mathrm{CD} 3+, \mathrm{CD} 4+$ and $\mathrm{CD} 8+\mathrm{T}$ cells, and elevated cytokine profile were reported in COVID-19 patient with liver injury [36, 51, 52] Furthermore, decreased CD3+, $\mathrm{CD} 4+$ and CD8 $+\mathrm{T}$ cell counts as well as elevated IL-6 and IL-10 are considered as potential risk factors in patients with COVID-19 developing severe liver injury $[9,36,37]$. These findings indicate that the crosstalk between hyperinflammation and dysregulated immune responses is involved in COVID-19-associated liver injury. We thus characterized this process into three phases: the immune activation stage, secondary hemophagocytic lymphohistiocytosis (sHLH) stage and immune suppression stage.

In the immune activation stage, the active replication of SARS-CoV-2 causes pyroptosis of target cells and releases pathogen-associated molecular patterns (PAMPs), such as viral RNA; damage-associated molecular patterns (DAMPs), including ATP, DNA and ASC oligomers; and proinflammatory cytokines and chemokines, including IL$1 \beta$, GM-CSF, CCL2 and CCL7 [53]. These inflammatory signals subsequently activate $\mathrm{T}$ and $\mathrm{B}$ cell immune responses and recruit macrophages and monocytes to the site of infection [54]. sHLH is a hyperinflammatory syndrome characterized by CRS. Activated T cells and NK cells produce large amounts of cytokines, such as interferon gamma (IFN- $\gamma$ ), tumor necrosis factor alpha (TNF- $\alpha$ ) and granulocyte-macrophage colony-stimulating factor (GM-CSF) to activate monocyte-derived macrophages $[42,55]$. Several alternative mechanisms that likely 


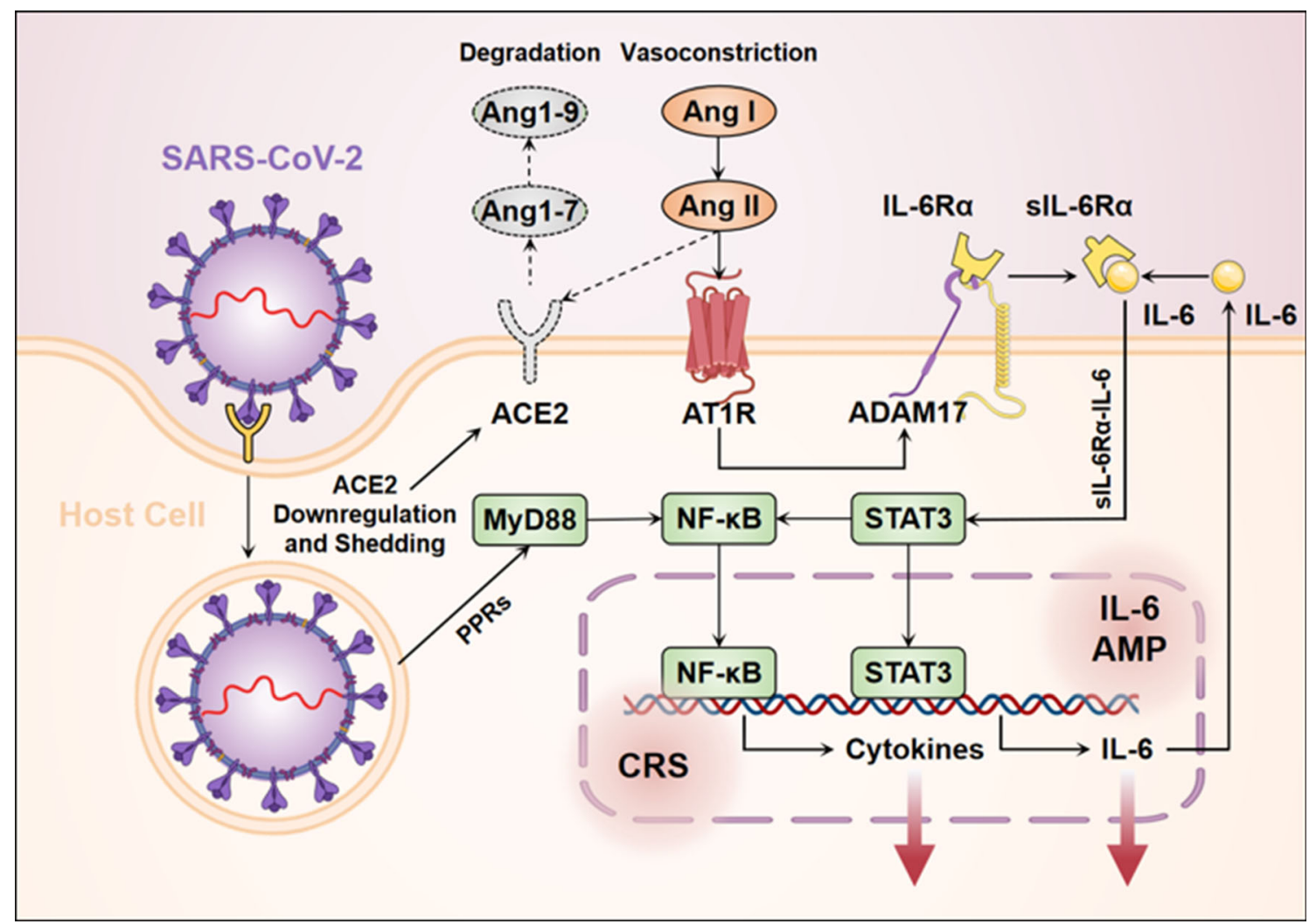

Fig. 2 Interaction between the renin-angiotensin system (RAS) and cytokine release syndrome (CRS). ACE2 is a key counterregulatory enzyme that degrades Ang II to Ang1-7. After the endocytosis of the viral complex, ACE2 is downregulated and shed from the surface of the host cell, resulting in angiotensin II accumulation. Ang II acts not only as a vasoconstrictor but also as a proinflammatory cytokine via the AT1R-metalloprotease 17 (ADAM17) axis. ADAM17 can cleave

contribute to the hyperactivation of monocyte-derived macrophages are illustrated in Fig. 3. Activated macrophages also produce additional IL- 6 and other inflammatory factors, resulting in a cytokine storm that causes severe immune damage to the lungs as well as the liver, heart, and kidneys; hence, sHLH is alternatively known as macrophage activation syndrome (MAS) [56, 57].

However, an immune suppression stage is also evident after the hyperinflammation stage. It is characterized by a drastic reduction in peripheral lymphocytes and an increase in the neutrophil-to-lymphocyte ratio [58, 59]. Profound lymphopenia is also found in COVID-19 associated liver injury as well $[9,36,51]$. Although an inhibitory receptor, NKG2A, has been found on lymphocytes in COVID-19 patients, the mechanisms underlying lymphopenia are still poorly understood [60]. The reduction in the number of peripheral lymphocytes in COVID-19 patients may be caused by the recruitment of immune cells from blood to inflamed tissues or the use of steroid treatment to mitigate inflammation [50]. Some studies have reported significant T-cell depletion in the secondary lymphoid organs of the membrane form of IL-6Ra, thereby generating soluble IL-6R, which binds to IL-6 and subsequently activates STAT3. This trans signaling results in CRS involving secretion of various proinflammatory cytokines and chemokines, including additional IL-6. Therefore, the feedback loop of the IL-6 amplifier (IL-6 Amp) might act as a switch to activate "cytokine storms"

patients infected with SARS-CoV or SARS-CoV-2 $[53,57]$. Whether the virus can directly infect $\mathrm{T}$ cells remains undetermined. Macrophages expressing IL-6 have been associated with severe depletion of lymphocytes in the spleen and lymph nodes. T-cell apoptosis and exhaustion resulting from defective activation due to dendritic cell dysfunction have been reported (Fig. 3) [42]. Therefore, during the treatment of COVID-19, liver function, inflammatory cytokines and $\mathrm{T}$ lymphocyte subsets should be closely monitored, which would help to propose new intervention strategies for COVID-19 patients with hepatic dysfunction.

\section{Abnormal coagulation and neutrophil extracellular traps (NETs)}

Abnormal coagulation is increasingly associated with poor prognosis and may be the main causes of organ failure and death in severe COVID-19 patients [53, 61, 62]. Depressed platelet counts, increased levels of fibrin degradation 


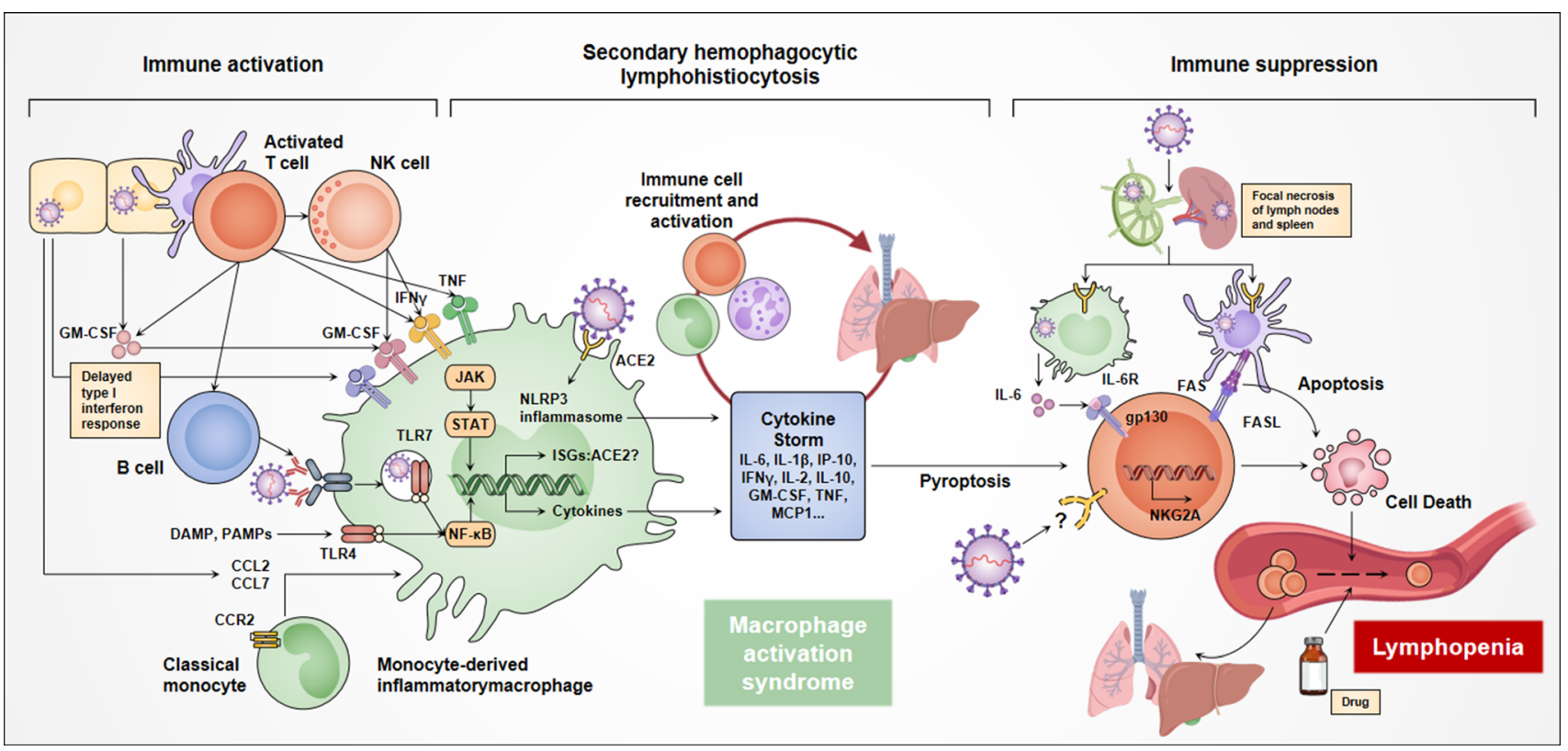

Fig. 3 Pathways leading to hyperinflammation and dysregulated immune responses. Inflammatory immunopathogenesis in response to SARS-CoV-2 infection can be summarized into three stages: the immune activation stage, secondary hemophagocytic lymphohistiocytosis (sHLH) stage and immune suppression stage. In the immune activation stage, the active replication of SARS-CoV-2 activate $\mathrm{T}$ and $\mathrm{B}$ cell immune responses and recruit macrophages and monocytes to the site of infection. sHLH is a hyperinflammatory syndrome characterized by CRS. Cytokines and chemokines released by host cells and activated $\mathrm{T}$ cells promote the recruitment and activation of

products (known as D-dimers), climbing neutrophil counts and neutrophil to lymphocyte ratios was observed in severe COVID-19 with hepatic dysfunction [4, 7, 63]. Liver biopsies from COVID-19 patients reported massive dilation of portal vein branches, luminal thrombosis, fibrin microthrombi and endothelitis in liver sinusoids as well as hepatocytes necrosis $[7,64,65]$. These findings support the hypothesis that COVID-19-associated liver damage might be partially caused by the abnormal coagulation process, derangement of blood circulation or endothelial damage.

However, the concrete mechanisms for the coagulation abnormalities observed in COVID-19 patients have not yet been defined. Whether SARS-CoV-2 is able to directly attack vascular endothelial cells by expressing high levels of ACE2 still need to be further explored. Nebuloni et al. detected the SAR-CoV-2 virions in the vessel lumen and endothelial cells by in situ hybridization, however, as they mentioned that these findings at present are insufficient to support any definite conclusion [7]. Notably, ACE2 is expressed on arterial and venous endothelial cells, where it functions as a counterregulatory enzyme to attenuate vasoconstriction and inflammation [43, 66]. Questions have been raised about whether the abnormal coagulation observed in COVID-19 patients is partly induced by the monocyte-derived macrophages. A delayed type I interferon response enhances cytopathic effects and recruit monocytes in blood to the infection site. The receptor ACE2 and viral particles have been observed in macrophages, indicating that SARS-CoV-2 may directly invade macrophages. In addition, ADE is the alternative mechanism leading to viral entry and the infection of macrophages. An immune suppression stage is also evident after the hyperinflammation stage. The potential mechanisms underlying lymphopenia are illustrated in the left panel

direct vascular damage caused by SARS-CoV-2 infection and/or ACE2 inhibition, possibilities that need to be further explored.

MAS and NETs have the potential to propagate inflammation and microangiopathy in cases of severe COVID-19 [53]. In the initiation of coagulation, endothelial cells are activated by cytokines or viral particles and produce monocyte chemoattractants and adhesion molecules. Monocytes are recruited to endothelial cells and express tissue factors (TFs) in response to proinflammatory stimuli, such as PAMPs, DAMPs, cytokines and chemokines. Tissue factor expressed by activated monocytes then activates an extrinsic coagulation pathway, leading to fibrin deposition and blood clotting (Fig. 4a) [67, 68]. Neutrophils are recruited early to sites of infection where they may exert antiviral effects. NETs are extracellular webs of chromatin, microbicidal proteins, and oxidant enzymes that are released by neutrophils to contain infections [69]. However, excessive NETs formation can trigger a cascade of inflammatory reactions and the activation pathway of contact coagulation, binding and activating platelets to amplify blood clotting (Fig. 4a) [70]. Thus, targeting MAS and NETs may alleviate COVID-19-associated liver injury. 

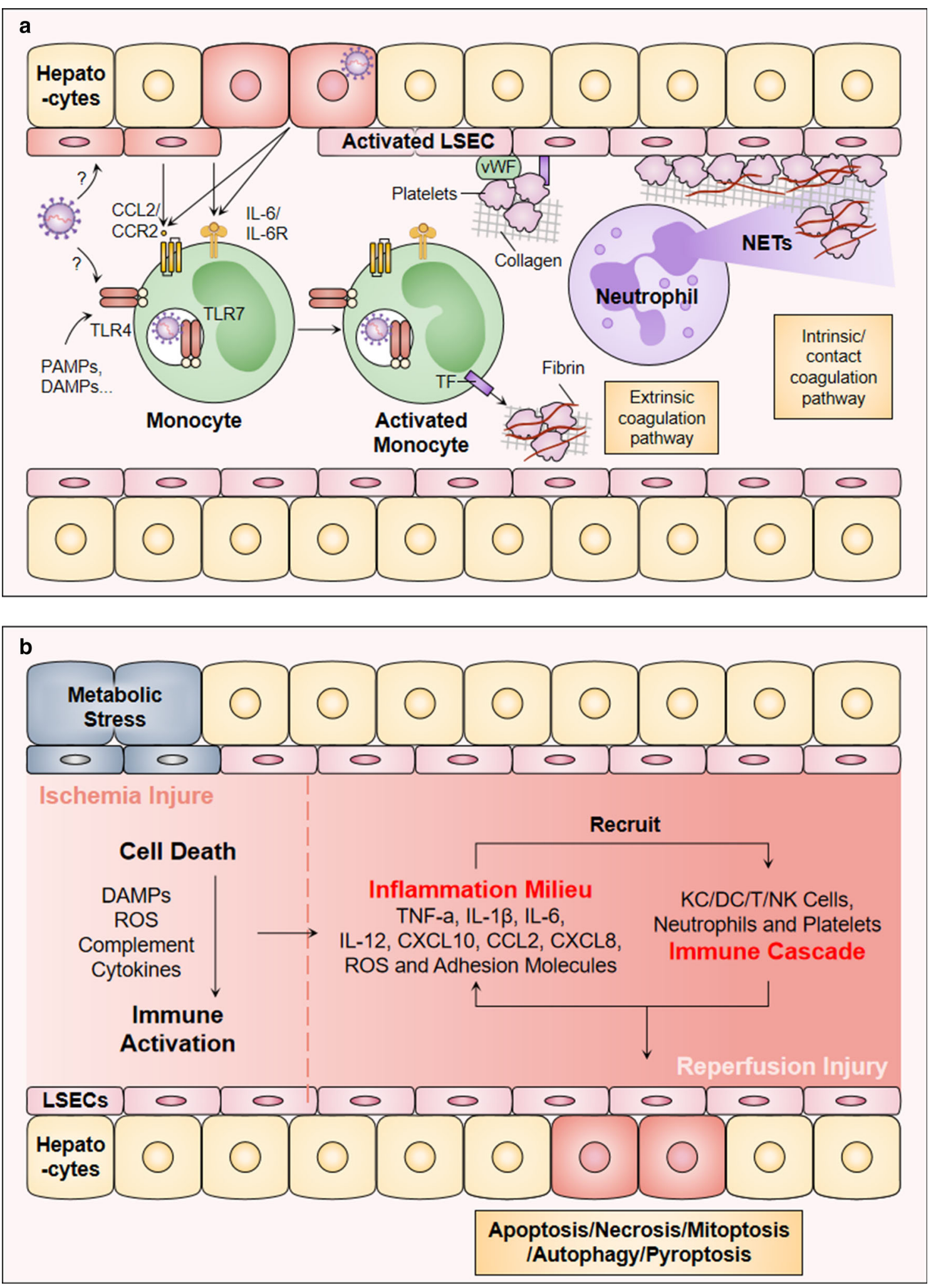
4Fig. 4 The mechanisms of abnormal coagulation and hepatic ischemia/hypoxia reperfusion injury in COVID-19-associated liver injury. a Abnormal coagulation has been significantly associated with poor prognosis for patients with severe COVID-19 with hepatic dysfunction. Monocytes are recruited to endothelial cells and express tissue factors (TFs) in response to proinflammatory stimuli, and then, activate an extrinsic coagulation pathway, leading to fibrin deposition and blood clotting. Neutrophils are recruited early to sites of infection and release neutrophil extracellular traps (NETs), which trigger a cascade of inflammatory reactions and the activation pathway of contact coagulation, binding and activating platelets to amplify blood clotting. b Hepatic ischemia/hypoxia reperfusion injury involves a biphasic process of ischemia-induced cell injury and reperfusioninduced inflammatory response. Ischemic injury, a localized process of cellular metabolic disturbances, leads to initial hepatocyte cell death. Reperfusion injury, which follows ischemic injury, results not only from metabolic disturbances but also from a profound inflammatory immune response that involves both direct and indirect cytotoxic mechanisms

\section{Hepatic ischemia/hypoxia-reperfusion injury}

COVID-19-associated hypoxia and hypotension might contribute to liver injury or even develop into liver failure [9]. Hypoxic hepatitis, also known as 'shock liver' can cause a sharp increase in aminotransferases in the setting of respiratory failure, shock, or cardiac failure, which may occur in severe COVID-19 [71, 72]. Ischemia/hypoxiareperfusion injury contributes to liver injury in hypoxic hepatitis, which involves a biphasic process of ischemiainduced cell injury and reperfusion-induced inflammatory response [73, 74]. Ischemic injury, a localized process of cellular metabolic disturbances resulting from lipid metabolism disorders, glycogen consumption, lack of oxygen supply and adenosine triphosphate depletion, leads to initial hepatocyte death [75]. Reperfusion injury, which follows ischemic injury, results not only from metabolic disturbances but also from a profound inflammatory immune response that involves both direct and indirect cytotoxic mechanisms. Released DAMPs upon cell death, activation of the complement cascade and mitochondrial reactive oxygen species production all contribute to immune activation in the liver after reperfusion, which involves multiple liver nonparenchymal cell types, including Kupffer cells, dendritic cells, T cells, NK cells and neutrophils [75, 76]. The ischemia-reperfusion-activated proinflammatory immune cascade sustains itself by recruiting peripheral immune cells from the circulation and is critical for the ultimate reperfusion injury in liver (Fig. 4b) [76]. All the aforementioned findings suggest that hepatic ischemia/hypoxia-reperfusion injury may be one of the possible mechanisms of liver injury in COVID-19.

\section{Pre-existing chronic liver disease (CLD)}

Preliminary data indicate $2-11 \%$ of patients with COVID19 had pre-existing chronic liver disease (CLD) and 14-53\% with COVID-19 developed hepatic dysfunction, particularly in severe COVID-19 [77]. Theoretically, patients with chronic liver disease including cirrhosis and liver cancer might be more susceptible to SARS-CoV-2 infection due to their systemic immunocompromised status [78]. Another patient category of concern is post-transplant and autoimmune liver disease patients receiving immunosuppressive therapy [79]. However, based on currently available evidence, patients with CLD do not appear to be at a higher risk of infection compared to other individuals in the general population [9, 80]. More direct clinical evidence needs to be further investigated. Notably, two other key questions raised by COVID-19 may appear in these patients: whether patients with CLD will tend to develop a severe COVID-19; and whether COVID-19 will further aggravate underlying CLD, leading to hepatic decompensation, liver failure or even death?

Cai et al. reported that the presence of abnormal liver tests and liver injury at admission had significantly higher risks of developing severe COVID-19 [5]. Recent evidence further indicates that COVID-19 patients with CLD were at increased risk for mortality and the relative risk was markedly higher in patients with cirrhosis and hepatic decompensation, even in the absence of respiratory symptoms at the time of diagnosis [81-83]. Mortality correlated strongly with baseline Child-Pugh class and model for end-stage liver disease (MELD) score [81, 82, 84]. Excessive inflammatory response associated with COVID-19 is considered as a trigger of acute-onchronic liver failure (ACLF) and decompensation in patients with cirrhosis [85, 86]. Two multicentre retrospective studies reported that ACLF was diagnosed in $28 \%$ and $11.6 \%$ of COVID-19 patients with cirrhosis in Italy and Asia, respectively [81, 82]. A recent multicentre study indicated the incidence of ACLF in COVID-19 patients with cirrhosis does not seem to be significantly higher than that in cirrhosis alone (55\% vs. $36 \% ; P=0.25)$, and the mortality was statistically similar to that of the cirrhosisalone group (30\% vs $20 \%, P=0.16$ ) [87]. Although there was significantly higher mortality or presence of ACLF in the COVID-19 patients group compared with the COVID19-alone group [87]. The limitation of this study is the relatively small number of cases in COVID-19 patients with cirrhosis group, thus these observations need to be investigated in larger cohorts.

Elements of the metabolic syndrome such as obesity, hypertension and diabetes are considered as risk factors for severe COVID-19 [86, 88]. Therefore, non-alcoholic fatty 
Table 1 Summary of drugs used for COVID-19 and the potential for liver injury

\begin{tabular}{|c|c|c|}
\hline Drug & Rationale for COVID-19 & Potential for liver injury \\
\hline Remdesivir & $\begin{array}{l}\text { Adenine analog/RNA polymerase inhibitor } \\
\text { used for Ebola }\end{array}$ & $\begin{array}{l}\text { Rapid elevation of aminotransferase; cytotoxicity and mitochondrial } \\
\text { toxicity }\end{array}$ \\
\hline Lopinavir/ritonavir & $\begin{array}{l}\text { Antiretroviral protease inhibitors used for HIV/ } \\
\text { AIDS }\end{array}$ & $\begin{array}{l}\text { High odds of liver injury; avoid use in patients with decompensated } \\
\text { cirrhosis }\end{array}$ \\
\hline Tocilizumab & $\begin{array}{l}\text { Interleukin } 6 \text { receptor antagonist; treat } \\
\text { cytokine storm in COVID-19 }\end{array}$ & $\begin{array}{l}\text { Short lived and asymptomatic serum aminotransferase elevation; } \\
\text { progressive jaundice has been reported consider risk of HBV } \\
\text { reactivation }\end{array}$ \\
\hline $\begin{array}{l}\text { Chloroquine/ } \\
\text { hydroxychloroquine }\end{array}$ & $\begin{array}{l}\text { Endosomal acidification fusion inhibitor; } \\
\text { interference with the cellular receptor ACE2 }\end{array}$ & Rare hepatic biochemistry abnormality and acute liver injury \\
\hline Methylprednisolone & $\begin{array}{l}\text { Synthetic corticosteroid that binds to nuclear } \\
\text { receptors to dampen proinflammatory } \\
\text { cytokines }\end{array}$ & $\begin{array}{l}\text { Risk of infections and viral shedding in patents with decompensated } \\
\text { liver cirrhosis; consider the risk of HBV reactivation }\end{array}$ \\
\hline Arbidol & $\mathrm{S}$ protein/ACE2 membrane fusion inhibitor & $\begin{array}{l}\text { Elevation of aminotransferase; potentially metabolized in liver; } \\
\text { caution in patients with liver cirrhosis }\end{array}$ \\
\hline Baricitinib & Janus kinase inhibitor & $\begin{array}{l}\text { Transient and mild elevation of aminotransferase; avoid use in } \\
\text { patients with decompensated cirrhosis }\end{array}$ \\
\hline Camostat & $\begin{array}{l}\text { Blocks TMPRSS } 2 \text { which is required for } \mathrm{S} \\
\text { protein priming }\end{array}$ & Risk of liver dysfunction and jaundice \\
\hline Anakinra & Interleukin 1 receptor antagonist & Minimal hepatic metabolism \\
\hline Emapalumab & $\begin{array}{l}\text { Monoclonal antibody targeting interferon- } \\
\text { gamma; treat cytokine storm in COVID-19 }\end{array}$ & Mild and transient ALT elevation \\
\hline Favipiravir/favilavir & $\begin{array}{l}\text { Guanine analogue/RNA polymerase inhibitor } \\
\text { approved for influenza }\end{array}$ & Elevation of aminotransferase \\
\hline Ribavirin & $\begin{array}{l}\text { RNA polymerase inhibitor used for hepatitis } \mathrm{C} \\
\text { virus }\end{array}$ & $\begin{array}{l}\text { Hemolysis caused by ribavirin could induce tissue hypoxia; increased } \\
\text { hepatic aminotransferases }\end{array}$ \\
\hline Oseltamivir & $\begin{array}{l}\text { Competitive viral neuraminidase enzyme } \\
\text { inhibitor }\end{array}$ & Rare hepatic biochemistry abnormality and acute liver injury \\
\hline Anticoagulation & $\begin{array}{l}\text { Coagulopathy is a common abnormality in } \\
\text { COVID-19 }\end{array}$ & No major adverse events were related to heparin \\
\hline Acetaminophen & Analgesic/antipyretic & Frequent elevation of aminotransferases; hepatocyte toxicity \\
\hline Azithromycin & Inhibits viral entry and endocytosis & Potentially metabolized in the liver \\
\hline
\end{tabular}

liver disease (NAFLD), also terms as metabolic dysfunction-associated fatty liver disease (MAFLD), is presumed to be related to the progression of severe COVID-19. Several retrospective studies demonstrated that patients with NAFLD had a higher risk of progression to severe COVID-19 and longer viral time [88-90]. Besides, noninvasive fibrosis scores appear to correlate with a higher risk of developing severe COVID-19 [91]. Compared with NAFLD, there is less evidence that chronic viral hepatitis affects the course of COVID-19. A retrospective study reported that COVID-19 patients with chronic HBV hepatitis had a worse prognosis including higher mortality and incidence of complications including ACLF [92]. Currently, more evidence is needed to confirm the relationship between COVID-19 and patients with autoimmune hepatitis, liver transplantation or liver cancer [86, 93]. Finally, considering the expression of ACE2 receptors in bile duct cells, whether COVID-19 aggravates cholestasis in patients with primary biliary cirrhosis and primary sclerosing cholangitis still needs further research. In short, preliminary data indicate that COVID-19 patients with CLD are more likely to develop a severe COVID-19 and have a higher risk of mortality. Thus, early isolation, intensive surveillance, and timely diagnosis are essential for these patients.

\section{Drug-induced liver injury}

Patients with COVID-19, especially severe and critically ill patients, are often treated with multiple drugs. It has been reported that more than $50 \%$ of COVID-19 patients received intravenous antibiotics [2], and $45 \%$ of these patients received more than two kinds of antibiotics in combined therapy for a duration of between 3 and 17 days [94]. Although there is currently no targeted antiviral strategy for COVID-19, many patients have been treated with oseltamivir, arbidol, lopinavir, ritonavir and other 


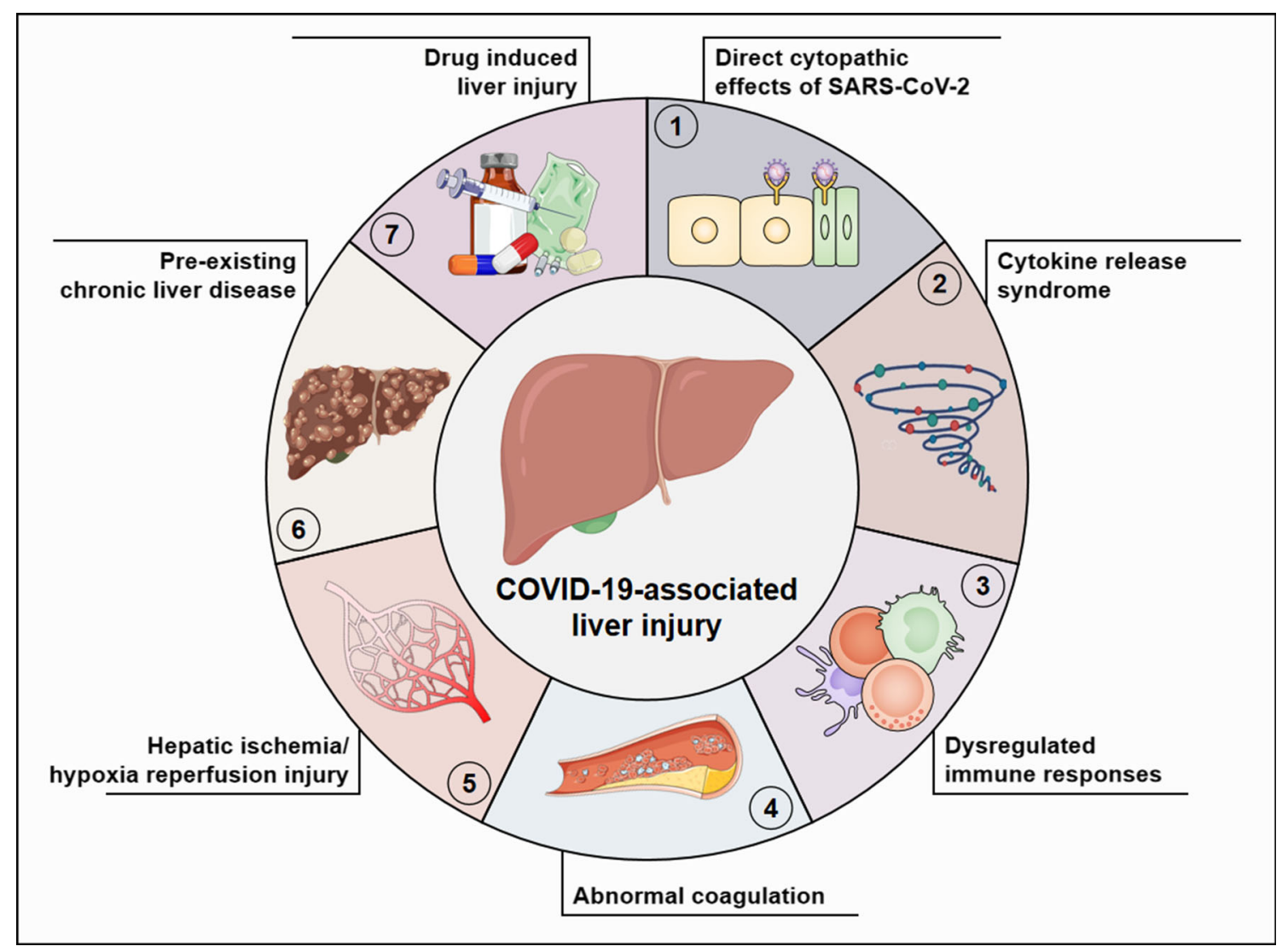

Fig. 5 The potential mechanisms of COVID-19-associated liver injury

antiviral drugs in clinical practice [3]. Compared with patients with normal liver function (31.3\%), patients with abnormal liver function (57.8\%) received a significantly higher proportion of lopinavir/ritonavir after admission [51]. Cai et al. reported that the use of lopinavir/ritonavir increased the odds of liver injury by fourfold [5]. Besides, patients often receive antipyretic agents, Chinese herbal decoctions and other symptomatic support drugs, which may also have some hepatotoxic effects. We have summarized the drugs used for COVID-19 and the potential for liver injury in Table 1.

Remdesivir, an adenosine-analogue induces RNA chain termination, attract our attention. It has been initially developed as an antiviral agent against Ebola and has currently emerged as a promising treatment candidate against COVID-19 [95]. Recent research reported that remdesivir was superior to placebo in shortening the time to recovery of hospitalized COVID-19 patients [96]. Whereas, in vitro experiments showed that Remdesivir and its metabolites were cytotoxic and mitochondrial toxic to a variety of cells, especially hepatocytes [97]. In a trial comparing remdesivir treatment for either 5 or 10 days, severe but not immediately life-threatening ALT/AST elevations were reported in $4-6 \%$ of patients and life- threatening AST/ALT elevations in 2-3\% of patients [98]. Although the rapid elevations of aminotransferase were observed, Beigel et al. and Wang et al. reported that there was no significant difference in the rate of aminotransferase elevation between COVID-19 patients taking remdesivir and placebo [99, 100]. Notably, both trials excluded patients with baseline alanine or aspartate aminotransferase more than five times the upper limit units and Wang et al. also excluded patients with cirrhosis. Thus, special attention should be paid to the potential liver toxicity of remdesivir in patients with severe chronic liver disease or with obvious hepatic enzyme abnormalities.

\section{Conclusions}

Liver injury, which significantly increases mortality, is common in COVID-19 patients. Whether SARS-CoV-2 can directly infect hepatocytes and/or cholangiocytes is still debated. Although virus particles seem to be observed in hepatocytes and hepatic endothelial cells, further evidence is needed to confirm the directly viral infection and its association with liver damage. Evidently, the direct effect of SARS-CoV-2 on the liver may not be fully 
achieved through ACE2, L-SIGN and CD147 may function as alternative receptors or as enhancer factors that facilitate ACE2-mediated SARS-CoV-2 infection. Furthermore, it is unknown/unclear if ADE may induce SARS-CoV-2 infection of hepatocytes as well.

The mechanisms underlying liver dysfunction in COVID-19 patients are not fully understood, which are likely multifactorial and related to the direct cytopathic effects of SARS-CoV-2, hyperinflammation, dysregulated immune responses, hypoxia, abnormal coagulation, preexisting chronic liver disease and drugs (Fig. 5). Although 14-53\% of patients with COVID-19 were reported to develop hepatic dysfunction, liver injury as the first manifestation in COVID-19 patients is relatively rare [77]. Moreover, severe COVID-19 patients with liver decompensation or liver failure were often accompanied by excessive systemic inflammation, dysregulated immune responses and metabolic disorders [85]. Thus, the interaction between local liver injury caused by direct cytopathic effects of SARS-CoV-2 and systemic disturbances needs to be further investigated. In conclusion, although some of our ideas may later prove to be imperfect or even incorrect, we believe that they may provide input and guidance for current basic and clinical research.

Acknowledgements This research was supported by Grants from the National Key Research and Development Program of China No. 2018YFC1312103 (L.X.), National Natural Science Foundation of China No. 81972237 (L.X.), No. 81772623 (L.X.), and No. 81772610 (D.T.).

Author contributions DL and XD performed the literature search and manuscript drafting. MX performed figure typesetting. DT and LX supervised and revised the manuscript.

\section{Compliance with ethical standards}

Conflict of interests The authors declare that they have no conflict of interest.

\section{References}

1. Zhu N, Zhang D, Wang W, et al. A novel coronavirus from patients with pneumonia in China, 2019. N Engl J Med. 2020;382:727-33.

2. Guan WJ, Ni ZY, Hu Y, et al. Clinical characteristics of coronavirus disease 2019 in China. N Engl J Med. 2020;382: 1708-20.

3. Zhang C, Shi L, Wang FS. Liver injury in COVID-19: management and challenges. Lancet Gastroenterol Hepatol. 2020;5:428-30.

4. Bangash MN, Patel J, Parekh D. COVID-19 and the liver: little cause for concern. Lancet Gastroenterol Hepatol. 2020;5: 529-30.

5. Cai Q, Huang D, Yu H, et al. COVID-19: abnormal liver function tests. J Hepatol. 2020;73:566-74.
6. Zhang Y, Zheng L, Liu L, Zhao M, Xiao J, Zhao Q. Liver impairment in COVID-19 patients: a retrospective analysis of 115 cases from a single centre in Wuhan city. China. Liver Int. 2020;40:2095-103.

7. Sonzogni A, Previtali G, Seghezzi M, et al. Liver histopathology in severe COVID 19 respiratory failure is suggestive of vascular alterations. Liver Int. 2020;40:2110-6.

8. Xu Z, Shi L, Wang Y, et al. Pathological findings of COVID-19 associated with acute respiratory distress syndrome. Lancet Respir Med. 2020;8:420-2.

9. Bertolini A, van de Peppel IP, Bodewes F, et al. Abnormal liver function tests in COVID-19 patients: relevance and potential pathogenesis. Hepatology. 2020;72:1864-72.

10. Pirola CJ, Sookoian S. SARS-CoV-2 virus and liver expression of host receptors: putative mechanisms of liver involvement in COVID-19. Liver Int. 2020;40:2038-40.

11. Wang Y, Liu S, Liu H, et al. SARS-CoV-2 infection of the liver directly contributes to hepatic impairment in patients with COVID-19. J Hepatol. 2020;73:807-16.

12. Wang Y, Lu F, Zhao J. Reply to: Correspondence relating to "SARS-CoV-2 infection of the liver directly contributes to hepatic impairment in patients with COVID-19." J Hepatol. 2020;73:996-8.

13. Philips CA, Ahamed R, Augustine P. SARS-CoV-2 related liver impairment-perception may not be the reality. J Hepatol. 2020;73:991-2.

14. Chau TN, Lee KC, Yao H, et al. SARS-associated viral hepatitis caused by a novel coronavirus: report of three cases. Hepatology. 2004;39:302-10.

15. Zhou P, Yang XL, Wang XG, et al. A pneumonia outbreak associated with a new coronavirus of probable bat origin. Nature. 2020;579:270-3.

16. Hoffmann M, Kleine-Weber H, Schroeder S, et al. SARS-CoV-2 cell entry depends on ACE2 and TMPRSS2 and is blocked by a clinically proven protease inhibitor. Cell. 2020;181:271.

17. Zou X, Chen K, Zou J, Han P, Hao J, Han Z. Single-cell RNAseq data analysis on the receptor ACE2 expression reveals the potential risk of different human organs vulnerable to 2019-nCoV infection. Front Med. 2020;14:185-92.

18. Wang $\mathrm{Z}, \mathrm{Xu} \mathrm{X}$. scRNA-seq profiling of human testes reveals the presence of the ACE2 receptor, a target for SARS-CoV-2 infection in spermatogonia, leydig and sertoli cells. Cells. 2020;9:920.

19. Han L, Wei X, Liu C, et al. Single-cell atlas of a non-human primate reveals new pathogenic mechanisms of COVID-19. bioRxiv. 2020. https://doi.org/10.1101/2020.04.10.022103.

20. Guan GW, Gao L, Wang JW, et al. Exploring the mechanism of liver enzyme abnormalities in patients with novel coronavirusinfected pneumonia. Zhonghua Gan Zang Bing Za Zhi. 2020;28:100-6.

21. Chai X, Hu L, Zhang Y, et al. Specific ACE2 expression in cholangiocytes may cause liver damage after 2019-nCoV infection. bioRxiv. 2020. https://doi.org/10.1101/2020.02.03. 931766.

22. Zhao B, Ni C, Gao R, et al. Recapitulation of SARS-CoV-2 infection and cholangiocyte damage with human liver ductal organoids. Protein Cell. 2020;11:771-5.

23. Han D, Fang Q, Wang X. SARS-CoV-2 was found in the bile juice from a patient with severe COVID-19. J Med Virol. 2021;93:102-4.

24. Han DP, Lohani M, Cho MW. Specific asparagine-linked glycosylation sites are critical for DC-SIGN- and L-SIGN-mediated severe acute respiratory syndrome coronavirus entry. J Virol. 2007;81:12029-39. 
25. Gardner JP, Durso RJ, Arrigale RR, et al. L-SIGN (CD 209L) is a liver-specific capture receptor for hepatitis $\mathrm{C}$ virus. P Natl Acad Sci USA. 2003;100:4498-503.

26. Jeffers SA, Tusell SM, Gillim-Ross L, et al. CD209L (L-SIGN) is a receptor for severe acute respiratory syndrome coronavirus. Proc Natl Acad Sci USA. 2004;101:15748-53.

27. Boily-Larouche G, Iscache AL, Zijenah LS, et al. Functional genetic variants in DC-SIGNR are associated with mother-tochild transmission of HIV-1. PLoS ONE. 2009;4:e7211.

28. Xiong L, Edwards CK 3rd, Zhou L. The biological function and clinical utilization of CD147 in human diseases: a review of the current scientific literature. Int J Mol Sci. 2014;15:17411-41.

29. Ulrich H, Pillat MM. CD147 as a target for COVID-19 treatment: suggested effects of azithromycin and stem cell engagement. Stem Cell Rev Rep. 2020;16:434-40.

30. Taylor A, Foo SS, Bruzzone R, Vu Dinh L, King NJC, Mahalingam S. Fc receptors in antibody-dependent enhancement of viral infections. Immunol Rev. 2015;268:340-64.

31. Katzelnick LC, Gresh L, Halloran ME, et al. Antibody-dependent enhancement of severe dengue disease in humans. Science. 2017;358:929-32.

32. Cao X. COVID-19: immunopathology and its implications for therapy. Nat Rev Immunol. 2020;20:269-70.

33. Fu Y, Cheng Y, Wu Y. Understanding SARS-CoV-2-mediated inflammatory responses: from mechanisms to potential therapeutic tools. Virol Sin. 2020;35:266-71.

34. Iwasaki A, Yang Y. The potential danger of suboptimal antibody responses in COVID-19. Nat Rev Immunol. 2020;20:339-41.

35. Channappanavar R, Perlman S. Pathogenic human coronavirus infections: causes and consequences of cytokine storm and immunopathology. Semin Immunopathol. 2017;39:529-39.

36. Zhan K, Liao S, Li J, et al. Risk factors in patients with COVID19 developing severe liver injury during hospitalisation. Gut. 2020. https://doi.org/10.1136/gutjnl-2020-321913.

37. Phipps MM, Barraza LH, LaSota ED, et al. Acute liver injury in COVID-19: prevalence and association with clinical outcomes in a large US cohort. Hepatology. 2020;72:807-17.

38. Schmidt-Arras D, Rose-John S. IL-6 pathway in the liver: from physiopathology to therapy. J Hepatol. 2016;64:1403-15.

39. Kishimoto $T$. Interleukin-6: from basic science to medicine40 years in immunology. Annu Rev Immunol. 2005;23:1-21.

40. Kang S, Tanaka T, Narazaki M, Kishimoto T. Targeting interleukin-6 signaling in clinic. Immunity. 2019;50:1007-23.

41. Hunter CA, Jones SA. IL-6 as a keystone cytokine in health and disease. Nat Immunol. 2015;16:448-57.

42. Moore JB, June $\mathrm{CH}$. Cytokine release syndrome in severe COVID-19. Science. 2020;368:473-4.

43. Mancia G, Rea F, Ludergnani M, Apolone G, Corrao G. Reninangiotensin-aldosterone system blockers and the risk of COVID19. N Engl J Med. 2020;382:2431-40.

44. Vickers C, Hales P, Kaushik V, et al. Hydrolysis of biological peptides by human angiotensin-converting enzyme-related carboxypeptidase. J Biol Chem. 2002;277:14838-43.

45. Lambert DW, Yarski M, Warner FJ, et al. Tumor necrosis factor-alpha convertase (ADAM17) mediates regulated ectodomain shedding of the severe-acute respiratory syndrome-coronavirus (SARS-CoV) receptor, angiotensin-converting enzyme-2 (ACE2). J Biol Chem. 2005;280:30113-9.

46. Wu HT, Chuang YW, Huang CP, Chang MH. Loss of angiotensin converting enzyme II (ACE2) accelerates the development of liver injury induced by thioacetamide. Exp Anim. 2018;67:41-9.

47. Sansoe G, Aragno M, Wong F. Pathways of hepatic and renal damage through non-classical activation of the renin-angiotensin system in chronic liver disease. Liver Int. 2020;40:18-31.
48. Neurath MF. COVID-19 and immunomodulation in IBD. Gut. 2020;69:1335-42.

49. Schett G, Sticherling M, Neurath MF. COVID-19: risk for cytokine targeting in chronic inflammatory diseases? Nat Rev Immunol. 2020;20:271-2.

50. Tay MZ, Poh CM, Renia L, MacAry PA, Ng LFP. The trinity of COVID-19: immunity, inflammation and intervention. Nat Rev Immunol. 2020;20:363-74.

51. Fan ZY, Chen LP, Li J, et al. Clinical features of COVID-19related liver functional abnormality. Clin Gastroenterol $\mathrm{H}$. 2020;18:1561-1566.

52. Kovalic AJ, Huang G, Thuluvath PJ, Satapathy SK. Elevated liver biochemistries in hospitalized chinese patients with severe COVID-19: systematic review and meta-analysis. Hepatology. 2020;21(10):1002.

53. Merad M, Martin JC. Pathological inflammation in patients with COVID-19: a key role for monocytes and macrophages. Nat Rev Immunol. 2020;20:355-62.

54. Feng G, Zheng KI, Yan QQ, et al. COVID-19 and liver dysfunction: current insights and emergent therapeutic strategies. J Clin Transl Hepatol. 2020;8:18-24.

55. Rasouli J, Ciric B, Imitola J, et al. Expression of GM-CSF in T cells is increased in multiple sclerosis and suppressed by IFNbeta therapy. J Immunol. 2015;194:5085-93.

56. Crayne CB, Albeituni S, Nichols KE, Cron RQ. The immunology of macrophage activation syndrome. Front Immunol. 2019;10:119.

57. Mehta P, McAuley DF, Brown M, et al. COVID-19: consider cytokine storm syndromes and immunosuppression. Lancet. 2020;395:1033-4.

58. Chen $\mathrm{G}, \mathrm{Wu} \mathrm{D}$, Guo W, et al. Clinical and immunological features of severe and moderate coronavirus disease 2019. J Clin Invest. 2020;130:2620-9.

59. Li H, Liu L, Zhang D, et al. SARS-CoV-2 and viral sepsis: observations and hypotheses. Lancet. 2020;395:1517-20.

60. Zheng M, Gao Y, Wang G, et al. Functional exhaustion of antiviral lymphocytes in COVID-19 patients. Cell Mol Immunol. 2020;17:533-5.

61. Manne BK, Denorme F, Middleton EA, et al. Platelet gene expression and function in patients with COVID-19. Blood. 2020;136:1317-29.

62. Tang N, Bai H, Chen X, Gong JL, Li DJ, Sun ZY. Anticoagulant treatment is associated with decreased mortality in severe coronavirus disease 2019 patients with coagulopathy. J Thromb Haemost. 2020;18:1094-9.

63. Wang D, Hu B, Hu C, et al. Clinical characteristics of 138 hospitalized patients with 2019 novel coronavirus-infected pneumonia in Wuhan. China. JAMA. 2020;323:1061-9.

64. Varga Z, Flammer AJ, Steiger P, et al. Endothelial cell infection and endotheliitis in COVID-19. Lancet. 2020;395:1417-8.

65. Duarte-Neto AN, de Almeida Monteiro RA, da Silva LFF, et al. Pulmonary and systemic involvement of COVID-19 assessed by ultrasound-guided minimally invasive autopsy. Histopathology. 2020;77(2):186-97.

66. Chen L, Li XJ, Chen MQ, Feng Y, Xiong CL. The ACE2 expression in human heart indicates new potential mechanism of heart injury among patients infected with SARS-CoV-2. Cardiovasc Res. 2020;116:1097-100.

67. van der Poll T, van de Veerdonk FL, Scicluna BP, Netea MG. The immunopathology of sepsis and potential therapeutic targets. Nat Rev Immunol. 2017;17:407-20.

68. von Bruhl ML, Stark K, Steinhart A, et al. Monocytes, neutrophils, and platelets cooperate to initiate and propagate venous thrombosis in mice in vivo. J Exp Med. 2012;209:819-35.

69. Zuo Y, Yalavarthi S, Shi H, et al. Neutrophil extracellular traps in COVID-19. JCI Insight. 2020;5:e138999. 
70. Barnes BJ, Adrover JM, Baxter-Stoltzfus A, et al. Targeting potential drivers of COVID-19: neutrophil extracellular traps. J Exp Med. 2020;217:e20200652.

71. Akhmerov A, Marban E. COVID-19 and the heart. Circ Res. 2020;126:1443-55.

72. Strnad P, Tacke F, Koch A, Trautwein C. Liver-guardian, modifier and target of sepsis. Nat Rev Gastroenterol Hepatol. 2017;14:55-66.

73. Peralta C, Jimenez-Castro MB, Gracia-Sancho J. Hepatic ischemia and reperfusion injury: effects on the liver sinusoidal milieu. J Hepatol. 2013;59:1094-106.

74. Zhang XJ, Cheng X, Yan ZZ, et al. An ALOX12-12-HETEGPR31 signaling axis is a key mediator of hepatic ischemiareperfusion injury. Nat Med. 2018;24:73-83.

75. Dar WA, Sullivan E, Bynon JS, Eltzschig H, Ju C. Ischaemia reperfusion injury in liver transplantation: cellular and molecular mechanisms. Liver Int. 2019;39:788-801.

76. Zhai Y, Petrowsky H, Hong JC, Busuttil RW, Kupiec-Weglinski JW. Ischaemia-reperfusion injury in liver transplantation-from bench to bedside. Nat Rev Gastroenterol Hepatol. 2013;10:79-89.

77. Jothimani D, Venugopal R, Abedin MF, Kaliamoorthy I, Rela M. COVID-19 and the liver. J Hepatol. 2020;73:1231-40.

78. Singh S, Khan A. Clinical characteristics and outcomes of coronavirus disease 2019 among patients with preexisting liver disease in the United States: a multicenter research network study. Gastroenterology. 2020;159:768.

79. Boettler T, Newsome PN, Mondelli MU, et al. Care of patients with liver disease during the COVID-19 pandemic: EASLESCMID position paper. JHEP Rep. 2020;2:100113.

80. Pawlotsky JM. COVID-19 and the liver-related deaths to come. Nat Rev Gastroenterol Hepatol. 2020;17:523-5.

81. Qi XL, Wang JT, Li XY, et al. Clinical course of COVID-19 in patients with pre-existing decompensated cirrhosis: initial report from China. Hepatol Int. 2020;14:478-82.

82. Iavarone M, D'Ambrosio R, Soria A, et al. High rates of 30-day mortality in patients with cirrhosis and COVID-19. J Hepatol. 2020;73:1063-71.

83. Sarin SK, Choudhury A, Lau GK, et al. Pre-existing liver disease is associated with poor outcome in patients with SARS CoV2 infection; The APCOLIS Study (APASL COVID-19 Liver Injury Spectrum Study). Hepatol Int. 2020;14:690-700.

84. Moon AM, Webb GJ, Aloman C, et al. High mortality rates for SARS-CoV-2 infection in patients with pre-existing chronic liver disease and cirrhosis: preliminary results from an international registry. J Hepatol. 2020;73:705-8.

85. Khan MU, Mushtaq K, Alkaabi SR. Acute on chronic liver failure-possibly the main culprit of increased mortality in COVID-19 patients with liver disease. Gastroenterology. 2020. https://doi.org/10.1053/j.gastro.2020.06.094.

86. Boettler T, Marjot T, Newsome PN, et al. Impact of COVID-19 on the care of patients with liver disease: EASL-ESCMID position paper after 6 months of the pandemic. JHEP Rep. 2020;2:100169.

87. Bajaj JS, Garcia-Tsao G, Biggins SW, et al. Comparison of mortality risk in patients with cirrhosis and COVID-19 compared with patients with cirrhosis alone and COVID-19 alone: multicentre matched cohort. Gut. 2020. https://doi.org/10.1136/ gutjnl-2020-322118.

88. Ji D, Qin E, Xu J, et al. Non-alcoholic fatty liver diseases in patients with COVID-19: a retrospective study. J Hepatol. 2020;73:451-453.

89. Gao F, Zheng KI, Wang XB, et al. Metabolic associated fatty liver disease increases coronavirus disease 2019 disease severity in nondiabetic patients. J Gastroenterol Hepatol. 2021;36:204-7.

90. Zhou YJ, Zheng KI, Wang XB, et al. Metabolic-associated fatty liver disease is associated with severity of COVID-19. Liver Int. 2020;40:2160-2163.

91. Targher G, Mantovani A, Byrne CD, et al. Risk of severe illness from COVID-19 in patients with metabolic dysfunction-associated fatty liver disease and increased fibrosis scores. Gut. 2020;69:1545-7.

92. Zou X, Fang M, Li S, et al. Characteristics of liver function in patients with SARS-CoV-2 and chronic HBV coinfection. Clin Gastroenterol Hepatol. 2020. https://doi.org/10.1016/j.cgh.2020. 06.017.

93. Garrido I, Liberal R, Macedo G. Review article: COVID-19 and liver disease-what we know on 1st May 2020. Aliment Pharm Ther. 2020;52:267-275.

94. Chen N, Zhou M, Dong X, et al. Epidemiological and clinical characteristics of 99 cases of 2019 novel coronavirus pneumonia in Wuhan, China: a descriptive study. Lancet. 2020;395:507-13.

95. Harrison C. Coronavirus puts drug repurposing on the fast track. Nat Biotechnol. 2020;38:379-81.

96. Beigel JH, Tomashek KM, Dodd LE. Remdesivir for the treatment of COVID-19-preliminary report. Reply N Engl J Med. 2020;383:994.

97. Ersin A, Minsun C, Lin L, et al. Elucidation of remdesivir cytotoxicity pathways through genome-wide CRISPR-Cas9 screening and transcriptomics. bioRxiv. 2020. https://doi.org/10. 1101/2020.08.27.270819.

98. Goldman JD, Lye DCB, Hui DS, et al. Remdesivir for 5 or 10 days in patients with severe COVID-19. N Engl J Med. 2020;383:1827-37.

99. Beigel JH, Tomashek KM, Dodd LE, et al. Remdesivir for the Treatment of Covid-19-Final Report. N Engl J Med. 2020;383:1813-26.

100. Wang Y, Zhang D, Du G, et al. Remdesivir in adults with severe COVID-19: a randomised, double-blind, placebo-controlled, multicentre trial. Lancet. 2020;395:1569-1578.

Publisher's Note Springer Nature remains neutral with regard to jurisdictional claims in published maps and institutional affiliations. 